\title{
Brain arteriovenous malformation treatment with transvenous endovascular technique after transarterial technique failure
}

Daniel Buzaglo Gonçalves 1*, Louise Makarem Oliveira 2, Moisés Buzaglo Salles 1, Lucas de Cristo Rojas Cabral 1, Maria Izabel Andrade dos Santos 1, Vitória Miki Pang Takatani 1, Gabriela Campos da Silva Coutinho 1, Massanobu Takatani 3, Carlos Michel Albuquerque Peres 4, Robson Luís Oliveira de Amorim 5.

${ }^{1}$ Graduate student, Faculdade de Medicina, Universidade Federal do Amazonas (UFAM), Amazonas, AM, Brazil.

${ }^{2}$ Medical doctor, Faculdade de Medicina, Universidade Federal do Amazonas (UFAM), Amazonas, AM, Brazil.

${ }^{3}$ Professor of Neurology, Faculdade de Medicina, Universidade Federal do Amazonas (UFAM), Amazonas, AM, Brazil.

${ }^{4}$ Neurosurgeon, Hemodinâmica, Hospital Santa Júlia (HSJ), Amazonas, AM, Brazil.

${ }^{5}$ Professor of Neurosurgery, Faculdade de Medicina, Universidade Federal do Amazonas (UFAM), Amazonas, AM, Brazil.

* Corresponding author: Daniel Buzaglo Gonçalves. Faculdade de Medicina, Universidade Federal do Amazonas. Rua Afonso Pena, 1053 - Centro, Manaus - AM, 69020-160, Manaus-Amazonas, Brasil. Phone: +55 (92) $3305-$ 1480. E-mail: danielbuzaglo13@gmail.com.

Research Ethics Committee Approval (if necessary): Not applicable.

Received on: May 17, 2021. Accepted on: May 25, 2021. Available online: May 27, 2021.

\begin{abstract}
Arteriovenous malformations (AVMs) are unnatural connections in the vascular system. The treatment strategies are dictated by the angioarchitecture, location and presentation of AVMs. The present study sought to report a case report of a 35-yearold female patient diagnosed with a brain AVM and submitted to a transvenous AVM embolization, located at the corpus callosum's splenium, after a previous transarterial embolization failure. As a therapeutic approach, the patient was submitted to transarterial embolization. However, the procedure was performed too proximally in the arteries, which resulted in the total AVM persistency. The patient was submitted to angiographic control until complete AVM occlusion.
\end{abstract}

Keywords: Arteriovenous Malformations; Therapeutics; Endovascular Procedures.

\section{Introduction}

Arteriovenous malformations (AVMs) are unnatural connections in the vascular system. Epidemiological studies showed that the incidence of
AVMs ranges from 1.12 to 1.42 cases per 100.000 individuals per year, with 38$68 \%$ of new cases presenting as firstever hemorrhage. Annual rates of hemorrhage in untreated AVMs have been estimated at $2.10-4.12 \%$ [1-2]. 
The brain AVMs can be associated with a broad spectrum of clinical manifestations - ranging from headaches and seizures to mass effect symptoms [3-4]. The main issue related to brain vascular malformations and patient's morbimortality is the presence of aneurysms and their rupture. Preventing intracranial bleeding is the primary purpose of AVMs treatment [56].

The treatment strategies are dictated by the angioarchitecture, location and presentation of AVMs. Currently employed treatment options include microsurgery, stereotactic radiosurgery, and endovascular embolization as standalone or combination therapies [7].

Surgical approach is usually performed from transarterial access, with arterial feeders disconnection followed by the draining vein ligation [8-9]. Nevertheless, the transvenous AVM embolization emerged as a feasible option, particularly in the following situations: small and compact AVM nidus, ruptured AVMs, AVMs without safe transarterial access, inaccessible residual nidus, incomplete microsurgery, and unsuccessful stereotactic radiosurgery [7].

On the downside, the transvenous access risks and benefits are still to be properly established due to a small number of reported cases, according to Chen and colleagues [7] The purpose of this study was to present a case report of a patient submitted to a transvenous AVM embolization after a previous transarterial embolization failure.

\section{Case report}

A 35-year-old female patient was diagnosed with a brain AVM, located at the corpus callosum's splenium. As a therapeutic approach, the patient was submitted to transarterial embolization. However, the procedure was performed too proximally in the arteries, which resulted in the total AVM persistency. Since then, the patient presented five episodes of intracranial bleeding.

After the last bleeding episode, the patient was admitted to an intensive care unit (ICU). Magnetic resonance imaging revealed intracranial hemorrhage (Figure 1), and a cerebral angiography was performed to evaluate the AVM. The exam showed dilated and tortuous entangled blood vessels with early venous opacification, characterizing the malformation (Figure $1)$.

The present AVM was located in the region between the right lateral ventricle posterior horn projection and the corpus callosum's splenium. The nidus measured $2 \mathrm{~cm}$ in its larger axis, with its opacification deriving from multiple tiny arterial supplies from the posterior cerebral artery. There was single vein drainage to the deep venous system, together with a stenosis in the level of its junction with Galen's vein.

Inside the surgical act, an occlusion in the junction between the 
posterior cerebral artery and the lateral occipital artery (P2P3 junction) was noticed through the arterial roadmapping, confirming that the previous embolization was made too proximally. Immediately, a Trevo $4 \times 20$ stent retriever was allocated, and the arterial reopening was confirmed. After that, an occlusion balloon was placed into the right $\mathrm{P} 2$ artery.

Subsequently, a Fargomini catheter was advanced into the straight sinus through jugular access. A
Headway Duo microcatheter $1.3 \mathrm{~F}$ was then advanced into the nidus through the draining vein, with microguidewire assistance. Alongside intermittent arterial occlusion, a total of 2 Squid 18 flasks were injected. The patient was submitted to angiographic control until complete AVM occlusion.

A final series of angiographic images demonstrated AVM radioanatomic cure, without any further complications (Figure 1).
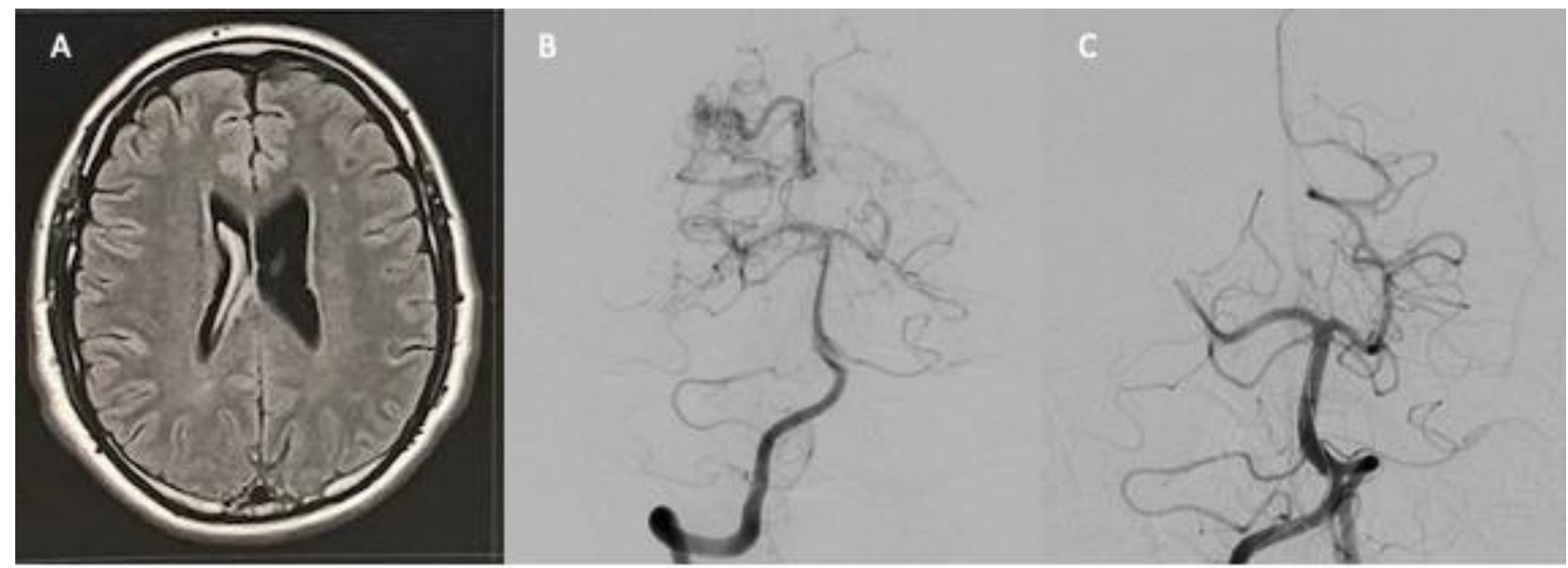

Figure 1. A. Right lateral ventricle hemorrhage seen through magnetic resonance. B. Nidus as showed in the angiography. C. Angiography imaging post embolization.

\section{Discussion}

There is an understanding that the bleeding risk in patients with AVMs grows at length. After classifying patients according to the Spetzler-Ponce grading system and evaluating each group association with hemorrhage, a review by Morgan et al. [10] concluded that even in the lowest classification (A), the patients benefited from surgical treatment [10].
Overall, approximately $42 \%$ of all intracranial hemorrhages cause permanent neurological deficit or death [10]. The patient's first surgery was through a failed transarterial approach and was followed by recurrent bleeding episodes.

One of the principal explanations for the AVM persistency has its basis on the endothelial cell theory. An incomplete nidus eradication induces the reminiscent endothelial cells to 
produce chemotactic and angiogenic substances due to the tissue's low oxygen level after the procedure. Consequently, cellular infiltration from the adjacent tissue and new vessel formation occurs. While the first leads to thrombus removal from the occluded vessel - thus reestablishing the blood flow, the latter provides irrigation to the thrombosed area. These factors ensure nidus blood supply and, therefore, its persistency [11].

After the previous failure, a retrograde vein pathway was used. This procedure is commonly attempted as salvage therapy, with restricted and specific indications. Some of them were present in the current patient, such as tiny perforating arteries and a single outflow vein $[7,10]$. As shown in a literature review by Chen et al. [7], in 13 studies with 69 patients, the transvenous approach obtained complete AVM obliteration in 93\% of the cases, which fit the procedure criteria [7].

Nevertheless, the transvenous surgery faces a different blood dynamic. Throughout the operation, the embolization needs to be done with minimal reflux, avoiding premature venous occlusion, distending the nidus, raising its pressure, and causing its rupture [7]. Massoud [12] and Murayama et al. [13] demonstrated that the irrigation artery occlusion reduces the pressure inside the nidus and in the draining vein, leading to an appropriate nidu's embolization hemodynamic control [12-13]. In the present study, an artery occlusion balloon was used to secure optimal blood flow and pressure handling. Moreover, the selected embolic substance was Squid 18, an ethylene-vinyl alcohol copolymer $(\mathrm{EVOH})$ based agent, which was demonstrated to be safe and effective in brain AVMs [14].

\section{Conclusion}

A transvenous embolization approach to treat brain AVMs with specific characteristics might work as an excellent therapeutic intervention, representing a possible alternative treatment to the usual transarterial access, with good relative results. Further clinical trials and long-term studies should be conducted to establish the technique's safety and efficacy throughout time.

\section{References}

[1] National Institute of Neurological Disorders and Stroke (NINDS). Arteriovenous Malformation Information Page. Retrieved Nov 16, 2019, from https:/ / www.ninds.nih.gov/Disorders /All-Disorders/Arte riovenousMalformation-Information-Page.

[2] Abecassis IJ, Xu DS, Batjer $\mathrm{HH}$, Bendok BR. Natural history of brain arteriovenous malformations: a systematic review. Neurosurg Focus. 2014 Sep;37(3):E7. doi: 10.3171/2014.6. FOCUS14250. 
[3] Rustam Al-Shahi, Charles Warlow. A systematic review of the frequency and prognosis of arteriovenous malformations of the brain in adults. Brain, Volume 124, Issue 10, October 2001. Pages 19001926. doi:10.1093/brain/124.10.1900.

[4] Benjamin M. The utility of neuroimaging in the evaluation of headache in patients with normal neurologic examinations. Frishberg Neurology. Jul 1994, 44 (7) 1191. doi: 10.1212/WNL.44.7.1191.

[5] Redekop G, TerBrugge K, Montanera W, Willinsky R. Arterial aneurysms associated with cerebral arteriovenous malformations: classification, incidence, and risk of hemorrhage. J Neurosurg. 1998 Oct;89(4):539-46. doi: 10.3171/jns.1998.89.4.0539.

[6] Kim H, Su H, Weinsheimer S, Pawlikowska L, Young WL. Brain arteriovenous malformation pathogenesis: a response-to-injury paradigm. Acta Neurochir Suppl. 2011; 111:83-92. doi:10.1007/978-3-7091-06938_14.

[7] Chen CJ, Norat P, Ding D, Mendes GAC, Tvrdik P, Park MS, Kalani MY. Transvenous embolization of brain arteriovenous malformations: a review of techniques, indications, and outcomes. Neurosurg Focus. 2018 Jul;45(1):E13. FOCUS 18113. doi: 10.3171/2018.3.
[8] Conger JR, Ding D, Raper DM, Starke RM, Durst CR, Liu KC, Jensen ME, Evans AJ. Preoperative Embolization of Cerebral Arteriovenous Malformations with Silk Suture and Particles: Technical Considerations and Outcomes. J Cerebrovasc Endovasc Neurosurg. 2016 Jun;18(2):90-99. doi: 10.7461/jcen.2016.18.2.90.

[9] Saatci I, Geyik S, Yavuz K, Cekirge HS. Endovascular treatment of brain arteriovenous malformations with prolonged intranidal Onyx injection technique: long-term results in 350 consecutive patients with completed endovascular treatment course. J Neurosurg. 2011 Jul;115(1):78-88. doi: 10.3171/2011.2. JNS 09830.

[10] Morgan MK, Davidson AS, Assaad NNA, Stoodley MA. Critical review of brain AVM surgery, surgical results and natural history in 2017. Acta Neurochir (Wien). 2017 Aug;159(8):1457-1478. doi: 10.1007/s00701-017-3217-x.

[11] Ramírez-Senent B, Abadal JM, Vázquez E, Lago I, Gálvez E, Araujo MA, de la Quintana MI. Endovascular Management of a Giant High-Flow Lower Limb Arteriovenous Malformation. Vasc Endovascular Surg. 2017 Nov;51(8):572-576. doi: $10.1177 / 1538574417731206$.

[12] Massoud TF. Transvenous retrograde nidus sclerotherapy under controlled hypotension (TRENSH): hemodynamic analysis and concept 
validation in a pig arteriovenous malformation model. Neurosurgery. 2013 Aug;73(2):332-42; discussion 342-3. doi:10.1227/01.neu.0000430765.80102.77.

[13] Murayama Y, Massoud TF, Viñuela F. Transvenous hemodynamic assessment of experimental arteriovenous malformations. Doppler guidewire monitoring of embolotherapy in a swine model. Stroke. 1996 Aug;27(8):1365-72. doi: 10.1161/01.str.27.8.1365.

[14] Akmangit I, Daglioglu E, Kaya T, Alagoz F, Sahinoglu M, Peker A, Derakshani S, Dede D, Belen D, Arat A. Preliminary experience with squid: a new liquid embolizing agent for AVM, AV fistulas and tumors. Turk Neurosurg. 2014;24(4):565-70. doi: 10.5137/1019-5149.JTN.11179-14.0.

Conflict of interest: The author declares no conflicts of interest.

Acknowledgements: Not applicable.

Funding: There was no funding regarding this article.

How to cite this article: Gonçalves DB, Oliveira LM, Salles MB, Cabral LCR, Santos MIA, Takatani VMP, Coutinho GCS, Takatani M, Peres CMA, Amorim RLO. Brain arteriovenous malformation treatment with transvenous endovascular technique after transarterial technique failure. Brazilian Journal of Case Reports. 2021 AbrJun;01(2):53-58. 